\title{
Prostate specific antigen testing policy worldwide varies greatly and seems not to be in accordance with guidelines: a systematic review
}

\author{
Saskia Van der Meer ${ }^{1}$, Sabine AM Löwik², Willem H Hirdes ${ }^{1}$, Rien M Nijman³ ${ }^{3}$ Klaas Van der Meer ${ }^{2}$,
} Josette EHM Hoekstra-Weebers ${ }^{4}$ and Marco H Blanker ${ }^{2^{*}}$

\begin{abstract}
Background: Prostate specific antigen (PSA) testing is widely used, but guidelines on follow-up are unclear. Methods: We performed a systematic review of the literature to determine follow-up policy after PSA testing by general practitioners (GPs) and non-urologic hospitalists, the use of a cut-off value for this policy, the reasons for repeating a PSA test after an initial normal result, the existence of a general cut-off value below which a PSA result is considered normal, and the time frame for repeating a test.

Data sources. MEDLINE, Embase, PsychInfo and the Cochrane library from January 1950 until May 2011.

Study eligibility criteria. Studies describing follow-up policy by GPs or non-urologic hospitalists after a primary PSA test, excluding urologists and patients with prostate cancer. Studies written in Dutch, English, French, German, Italian or Spanish were included. Excluded were studies describing follow-up policy by urologists and follow-up of patients with prostate cancer. The quality of each study was structurally assessed.
\end{abstract}

Results: Fifteen articles met the inclusion criteria. Three studies were of high quality. Follow-up differed greatly both after a normal and an abnormal PSA test result. Only one study described the reasons for not performing follow-up after an abnormal PSA result.

Conclusions: Based on the available literature, we cannot adequately assess physicians' follow-up policy after a primary PSA test. Follow-up after a normal or raised PSA test by GPs and non-urologic hospitalists seems to a large extent not in accordance with the guidelines.

Keywords: Prostate specific antigen, PSA, Follow-up, General practitioners, Non-urologic hospitalists, Guidelines, Systematic review

\section{Background}

Recently, Vedel et al. showed that although most guidelines are cautious about screening for prostate cancer, using PSA tests is routine practice in a variety of healthcare systems, both in North America and Europe [1].

The effect of prostate cancer screening on mortality and quality of life remains unclear [2]. Even after the European Randomised Study of Screening for Prostate Cancer (ERSPC) - the only study that showed a clear

\footnotetext{
* Correspondence: blanker@belvederelaan.nl

${ }^{2}$ Department of General Practice, University of Groningen, University Medical Center Groningen, Hanzeplein 1, P.O.Box 30.001, 9700, RB, Groningen, The Netherlands

Full list of author information is available at the end of the article
}

positive effect on prostate specific mortality - it is unknown which patients may benefit from screen-detected early diagnosis [3]. Still, Prostate Specific Antigen (PSA) tests are used regularly in patients with and without lower urinary tract symptoms (LUTS) [4-6].

The PSA test has several limitations: Due to its low specificity, an elevated PSA level does not necessarily indicate the presence of prostate cancer, as it can also be caused by benign prostate hyperplasia (BPH), urinary retention or prostatitis. Furthermore, test sensitivity at the applied normal values is suboptimal: a normal PSA value does not rule out prostate cancer $[7,8]$. Also, an abnormal PSA test result can have a great impact on a patients' mental health [9]. 
Because of these difficulties, guidelines on the use of the PSA test have been developed. The American Urological Association (AUA) PSA Best Practice Statement Update 2009 recommends to start regular screening for prostate cancer at the age of 40 years in patients with an anticipated lifespan of more than 10 years [9]. They no longer mention a threshold value of PSA to prompt follow-up, but advise basing the decision primarily on PSA and Digital Rectal Examination (DRE) results. Also, free and total PSA, patient's age, PSA velocity, PSA density, family history, ethnicity, prior biopsy history and comorbidities need to be taken into account [9]. The European Association of Urology (EAU) recommends follow-up after an abnormal DRE or elevated serum PSA measurement, with a cut-off level of $<2.5-3 \mathrm{ng} / \mathrm{ml}$ for younger men [10]. The European Society for Medical Oncology does not recommend screening for prostate cancer. However, they do advise prostate biopsies after an abnormal DRE or elevated PSA values, although no PSA cut-off value is mentioned [11].

It is unclear whether (and how) physicians use these guidelines and what cut-off values are being considered in daily practice. Especially follow-up by non-urologists is not clearly described in the literature. We conducted a systematic review of the literature on how follow-up after PSA testing is being conducted. We focused on the following questions. What is the policy of general practitioners (GPs) and non-urologic hospitalists after an abnormal PSA test result and can a cut-off value be determined for this policy? What are the reasons for repeating a PSA test after an initial normal result, what is the cut-off value used for a normal PSA test result and what is the time frame for repeating the test?

\section{Methods}

\section{Identification and selection of the literature}

In November 2009, a search of the literature was performed in duplicate (SM and SAML) to identify relevant publications on follow-up by GPs and non-urologic hospitalists after a PSA test. We used MEDLINE, Embase, PsycInfo and the Cochrane library to search for articles published from 1950 until October 2009. This search was updated in May 2011. The terms general practitioner and non-urologic hospitalist were linked by the Boolean operator OR. The Boolean operator AND linked these terms to the term PSA and to the terms follow-up or referral or consultation. For all these keywords one or more synonyms were used and all items were searched using "All fields" (Additional file 1: Appendix 1).

We included studies if the following criteria were met: study contained original data, it described actions undertaken by GPs or non-urologic specialists following an initial PSA test (no action, repeat the test, or referral to a urologist), and the article was written in Dutch, English,
French, German, Italian or Spanish. Excluded were studies describing actions undertaken by urologists and studies on patients with prostate cancer. Titles and abstracts of the identified studies were checked and the full text of these publications were read to find out whether inclusion criteria were met. Also, we screened reference lists of all relevant articles for other relevant studies. We contacted the authors if an article did not provide enough information to adequately assess inclusion criteria.

The main characteristics of the included publications were extracted by two authors (SM and SAML) using standardized forms.

\section{Quality assessment}

A difference in validity of included studies may affect the conclusions of a systematic review. Therefore, we assessed the quality of each study: two reviewers (SM and SAML) independently scored the quality of the included studies using a set of criteria. These criteria were a combination of the quality criteria described by Harden et al. and Prins et al. [12,13]. Each item was scored a "0" if the criterion was not met or if it was unclear whether the criterion was fulfilled, a "1" was given when that particular criterion was fulfilled. The sum of these scores indicated the quality score for each study. Disagreement was resolved by consensus or by a third reviewer (WHH) in case of persisting disagreement. The preferred study design was a prospective cohort study. In our study, 10 quality items and 5 informativity items were scored (Additional file 1: Appendix 2). The informativity score was not included in the quality score, as this reflects the quality of the manuscript rather than the quality of the study. Studies receiving more than $75 \%$ of the quality points (more than 7 points) were considered studies of high quality. The quality of database studies was assessed using the same scoring system, but three items of this system did not apply to this type of research, thus restricting the total score of these studies to 7 points and therefore defining a high quality database study as a study with more than 5 points.

\section{Data analysis}

Most studies in this review were too heterogeneous in their study design to apply statistical analysis of the data. We compared the results of the studies included using the quality score and study design (survey study or database study).

\section{Results}

\section{Selection and quality of studies}

No search results were found in the Cochrane Library. Embase identified a total of 2,614 titles. From MEDLINE 1,520 titles were extracted. PsychInfo revealed 19 articles. After reviewing title and abstract 31 articles were read 
fulltext. Fourteen articles met our inclusion criteria. Screening the reference list of these articles revealed one additional study meeting the inclusion criteria (Figure 1) [6,7,14-26].

Study characteristics of the 15 included studies are presented in Table 1. Three studies were database related, one study combined questionnaires with database research, and 11 studies were questionnaire-based. One study comprised of an abstract only.

The study population of the questionnaire studies varied between 48 and 658 physicians. The response rate varied from $28 \%$ to $90 \%$. The database studies had study populations varying from 94 to 1,647 patients. One database study only included patients of 75 years or older.

Quality scores are presented in Tables 1 and 2. Three survey studies and one database study were of high quality. On average, 2.8 items (range $0-5$ ) on external validity were scored positively as were 2.8 items (range $1-5$ ) on internal validity.

\section{Referral rate after normal PSA test}

As most studies defined a PSA $<4 \mathrm{ng} / \mathrm{ml}$ as normal, this value was chosen to differentiate between a normal and abnormal PSA test result (Tables 3 and 4). After a normal PSA test result (PSA $<4$, or PSA $\leq 4$, or age-specific cut off values, Table 3) referral was described in 2 studies $[14,23]$, and varied from 0\% reported by GPs to $28.6 \%$ referred by GPs and internists [14,23].

\section{Referral rate after moderately increased PSA ( $\geq 4 \mathrm{ng} / \mathrm{ml}$ )}

Three database studies showed a referral rate of 31 to $86 \%$ after a PSA $\geq 4 \mathrm{ng} / \mathrm{ml}$ (Table 4). More patients were referred in the USA $[14,16,19,21,25]$ than in Spain [24], and internists [21] referred more often than GPs [19,22-24]. Seven survey studies described referral in 10.5 to $100 \%$ of the PSA values $>4 \mathrm{ng} / \mathrm{ml}$ (Table 4 ). GPs mentioned referring more often compared to primary care practitioners (PCPs) [18-20,22-25]. Non-urologic hospitalists mentioned referring equally often as PCPs $[16,17,21,22,25]$. One study reported high overall referral rates for GPs (85.5\%)

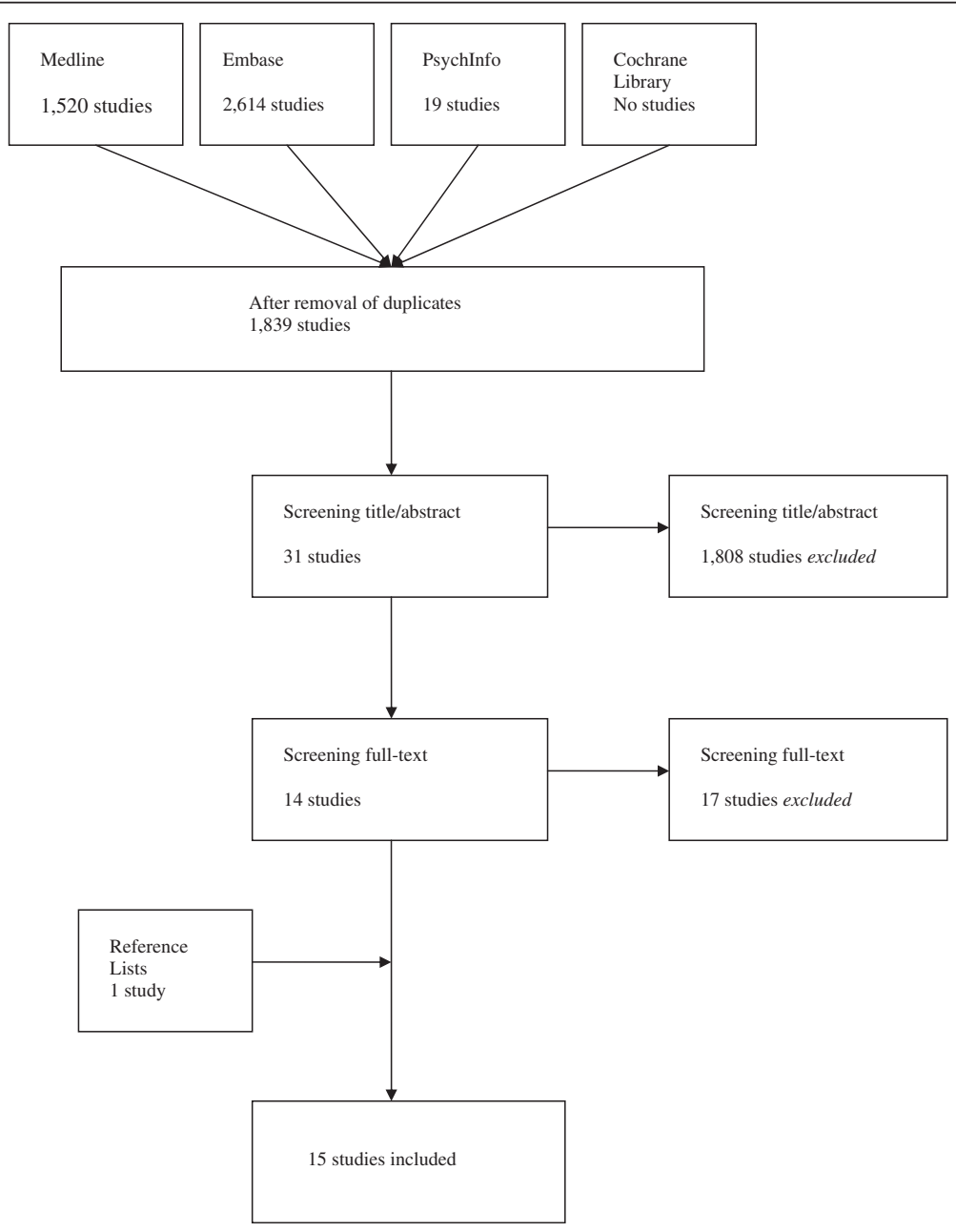

Figure 1 Systematic review flow diagram. 
Table 1 Characteristics of included studies

\begin{tabular}{|c|c|c|c|c|c|c|}
\hline $\begin{array}{l}\text { Reference } \\
\text { number }\end{array}$ & Year & Country & Design & Participants & Source population and response rate & QS \\
\hline [14] & 2006 & USA & Database & GPs \& internists & $\begin{array}{l}505 \text { patients aged } 75 \text { years or older, not previously diagnosed with } \\
\text { prostate cancer who underwent a PSA test between } 1998 \text { and } 2004\end{array}$ & 4 \\
\hline [24] & 2000 & Spain & Database & GP & $\begin{array}{l}94 \text { patients not previously diagnosed with prostate cancer with a PSA } \geq 4 \\
\text { in } 1998 \text {, selected from the pertinent laboratory }\end{array}$ & 6 \\
\hline [21] & 1998 & USA & Database & Internists & $\begin{array}{l}\text { 1,448 patients not previously diagnosed with prostate cancer who in } 1993 \\
\text { underwent a PSA test }\end{array}$ & 5 \\
\hline [23] & 2008 & UK & $\begin{array}{l}\text { Database } \\
\text { \& survey }\end{array}$ & GPs & $\begin{array}{l}\text { Database: } 709 \text { patients pre-guideline launch and } 1,040 \text { men post-guideline } \\
\text { launch with PSA } \geq 3 \mathrm{ng} / \mathrm{ml} \text { and } \geq 1 \text { PSA test by GPS }\end{array}$ & $\begin{array}{l}7 \\
(s u\end{array}$ \\
\hline
\end{tabular}

515 patients pre-guideline launch and 607 post-guideline launch with normal test-result $(<3)$ (random $25 \%$ sample of normal PSA tests by GP)

Questionnaire: 69 GPs from England and Wales, registered for PSA testing with the National External Quality Assessment Service, 48 responded, response rate $70 \%$

\begin{tabular}{|c|c|c|c|c|c|}
\hline 2008 & France & Survey & GPs & $\begin{array}{l}\text { All 1,339 GPs in Auvergne (France) registered with the Urssaf in 2006, } 658 \\
\text { responded, response rate } 49,1 \%\end{array}$ & 5 \\
\hline 2008 & UK & Survey & GPs & $\begin{array}{l}502 \text { PCPs in West Suffolk and Ipswich Hospital area (UK), } 192 \text { responded, } \\
\text { response rate 38\% }\end{array}$ & 6 \\
\hline 2005 & Denmark & Survey & GPs & $\begin{array}{l}325 \text { GPs in Northern Denmark (23\% woman), } 291 \text { responded, response } \\
\text { rate 90\% }\end{array}$ & 8 \\
\hline 2003 & Ireland & Survey & GPs & $\begin{array}{l}400 \text { GPs from Northern Ireland randomly selected by computer, } 282 \\
\text { responded, response rate } 71 \%\end{array}$ & 6 \\
\hline 2002 & UK & Survey & GPs & $\begin{array}{l}200 \text { GPs registered in the East Surrey region, } 118 \text { responded, response rate } \\
59 \%\end{array}$ & 2 \\
\hline 1995 & USA & Survey & GPs & $\begin{array}{l}\text { All } 149 \text { OAFP GPs from the Oklahoma City area and } 151 \text { randomly selected } \\
\text { OAFP physicians outside this area, } 152 \text { responded, response rate } 53 \%\end{array}$ & 9 \\
\hline \multirow[t]{4}{*}{ [22] } & \multirow[t]{4}{*}{ UK } & \multirow[t]{4}{*}{ Survey } & \multirow{4}{*}{$\begin{array}{l}\text { GPs/general } \\
\text { surgeons/ } \\
\text { geriatricians/FHSA }\end{array}$} & $\begin{array}{l}500 \text { GPs, associated with the Western General Infirmary in Edinburgh, } \\
\text { Scotland, } 118 \text { responded, response rate } 23,6 \%\end{array}$ & \multirow[t]{4}{*}{4} \\
\hline & & & & 373 general surgeons, 85 responded, response rate $22,8 \%$ & \\
\hline & & & & 712 geriatricians, 160 responded, response rate $22,5 \%$ & \\
\hline & & & & $\begin{array}{l}115 \text { FHSAs, } 58 \text { responded, response rate 50,4\% (and } 320 \text { urologists, results } \\
\text { excluded from this SR) }\end{array}$ & \\
\hline 2007 & Japan & Survey & $\begin{array}{l}\text { Internists/general } \\
\text { surgeons (PCP) }\end{array}$ & $\begin{array}{l}935 \text { PCPs (internist and general surgeons not in hospital and no urologist) } \\
\text { in South metropolitan Tokyo, } 281 \text { responded, mean response rate 30\% } \\
\text { (varying per question) }\end{array}$ & 5 \\
\hline 1998 & USA & Survey & GPs/internists (PCP) & $\begin{array}{l}\text { All physicians from the AMARP, listing themselves in general internal } \\
\text { medicine, family medicine (or urology, results excluded in this SR). } 444 \\
\text { PCPs responded, response rate } 51 \%\end{array}$ & 6 \\
\hline 1996 & USA & Survey & GPs/internists (PCP) & $\begin{array}{l}1.816 \text { PCPs randomly selected from all Arizona-licensed physicians from } \\
\text { the BMESA who selfreported to be GP, family practitioner or internist. } 68 \\
\text { were subsequently excluded (various reasons) and } 57 \text { were unreachable. } \\
\text { Overall, } 141 \text { eligible physicians completed the survey, response rate } 42,9 \%\end{array}$ & 10 \\
\hline 1996 & USA & Survey & $\begin{array}{l}\text { Internists/medical } \\
\text { subspecialists (PCP) }\end{array}$ & $\begin{array}{l}\text { All PCPs in Brooklyn, New York with the MSSNY, } 311 \text { PCPs responded, } \\
\text { response rate } 28 \% \text {, including } 134 \text { GPs }(43,1 \%) \text { and } 177 \text { internists/medical } \\
\text { subspecialists }(56,9 \%)\end{array}$ & 4 \\
\hline
\end{tabular}

Table order according to study design (database or survey studies), participants (starting with GPs) and year of publication (starting with most recent publications) Abbreviations: QS Quality Score; PCP Primary Care Physician; GP General Practitioner; OAFP Oklahoma Academy of Family Physicians; SR Systematic Review; FHSA Family Health Service Advisor; AMARP American Medical Association Registry of Physicians; BMESA Board of Medical Examiners of the State of Arizona; MSSNY Medical Society of the State of New York.

* abstract only. 
Table 2 Quality scores of included studies

\begin{tabular}{|c|c|c|c|c|c|c|c|c|c|c|c|c|c|c|c|c|c|c|c|c|}
\hline \multirow[t]{2}{*}{ Reference number } & \multirow[t]{2}{*}{ Year } & \multicolumn{6}{|c|}{ External validity } & \multicolumn{6}{|c|}{ Internal validity } & \multicolumn{6}{|c|}{ Informativity } & \multirow[t]{2}{*}{ Disagree } \\
\hline & & $a$ & b & c & d & e & sum & $f$ & g & $h$ & i & j & sum & $\mathrm{k}$ & $I$ & $\mathrm{~m}$ & $\mathrm{n}$ & o & sum & \\
\hline \multicolumn{21}{|l|}{ Questionnaire studies } \\
\hline$[23]$ & 2008 & 0 & 1 & 1 & 0 & 1 & 3 & 1 & 0 & 1 & 1 & 1 & 4 & 1 & 1 & 1 & 1 & 1 & 5 & $d, f, h$ \\
\hline [18] & 2008 & 0 & 0 & 0 & 1 & 1 & 2 & 1 & 0 & 1 & 1 & 0 & 3 & 1 & 1 & 1 & 1 & 1 & 5 & g \\
\hline$[26]$ & 2008 & 1 & 1 & 0 & 1 & 0 & 3 & 1 & 0 & 0 & 1 & 1 & 3 & 1 & 1 & 1 & 0 & 0 & 3 & $\mathrm{n}$ \\
\hline [17] & 2007 & 1 & 1 & 0 & 0 & 0 & 2 & 1 & 1 & 0 & 1 & 0 & 3 & 1 & 1 & 1 & 0 & 0 & 3 & $d, n$ \\
\hline [7] & 2005 & 1 & 1 & 1 & 1 & 0 & 4 & 1 & 1 & 0 & 1 & 1 & 4 & 1 & 1 & 1 & 1 & 1 & 5 & \\
\hline$[6]$ & 2003 & 0 & 1 & 1 & 1 & 0 & 3 & 1 & 0 & 0 & 1 & 1 & 3 & 0 & 1 & 1 & 1 & 1 & 4 & \\
\hline$[15]^{\mathrm{i}}$ & 2002 & 0 & 0 & 0 & 0 & 0 & 0 & 1 & 0 & 0 & 0 & 1 & 2 & 0 & 1 & 1 & 0 & 0 & 2 & $d, k$ \\
\hline [16] & 1998 & 1 & 1 & 0 & 1 & 0 & 3 & 1 & 1 & 0 & 1 & 0 & 3 & 1 & 1 & 1 & 1 & 1 & 5 & \\
\hline [20] & 1996 & 1 & 1 & 1 & 1 & 1 & 5 & 1 & 1 & 1 & 1 & 1 & 5 & 0 & 1 & 1 & 1 & 1 & 4 & i \\
\hline [25] & 1996 & 0 & 1 & 0 & 0 & 0 & 1 & 1 & 1 & 0 & 1 & 0 & 3 & 0 & 1 & 1 & 1 & 1 & 4 & d \\
\hline [19] & 1995 & 1 & 1 & 1 & 1 & 1 & 5 & 1 & 0 & 1 & 1 & 1 & 4 & 0 & 1 & 1 & 1 & 1 & 4 & $\mathrm{I}, \mathrm{O}$ \\
\hline [22] & 1995 & 0 & 0 & 0 & 1 & 0 & 1 & 1 & 0 & 0 & 1 & 1 & 3 & 1 & 1 & 0 & 1 & 1 & 4 & $\mathrm{i}, \mathrm{m}$ \\
\hline \multicolumn{21}{|l|}{ Database studies ii } \\
\hline [14] & 2006 & 1 & 1 & - & 0 & 1 & 3 & 0 & - & - & 1 & 0 & 1 & 1 & 1 & 1 & 1 & 1 & 5 & d \\
\hline [24] & 2000 & 1 & 1 & - & 1 & 1 & 4 & 0 & - & - & 1 & 1 & 2 & 0 & 1 & 1 & 1 & 1 & 4 & \\
\hline$[21]$ & 1998 & 1 & 1 & - & 0 & 1 & 3 & 0 & - & - & 1 & 1 & 2 & 1 & 1 & 1 & 1 & 1 & 5 & \\
\hline
\end{tabular}

ibstract only.

ii Categories C, g and h did not apply to database studies (-).

and non-urologic hospitalists (79-100\%) compared to the other studies [22]. This was also the only study describing high percentage of follow-up for non-urologic hospitalists.

\section{Referral rate after clearly increased PSA (> $10 \mathrm{ng} / \mathrm{ml}$ )}

One survey reported that $93 \%$ of the physicians (GPs) referred at PSA > $10 \mathrm{ng} / \mathrm{ml}$ [19]. However, three other surveys mentioned that only 13\%, $28 \%$ and $20 \%$ of the physicians (GPs/PCPs) respectively referred at PSA $>10 \mathrm{ng} / \mathrm{ml}[15,17,20]$.

Reported referral rates in the USA were 33\% in 1995 (GPs), 60\% and 86\% in 1998 (PCPs, internists and GPs respectively, Table 3) [16,19], and $52 \%$ in 2006 (GPs) [14,21]. In the UK, referral rates were $86 \%$ and $30 \%$ in 1995 and 2008, respectively (all GPs) [22,23]. Cut off values for referral were reported in 4 studies and varied

Table 3 Follow-up after normal PSA values

\begin{tabular}{|c|c|c|c|c|c|}
\hline Reference number & Country & Cut off (ng/ml) & Referral (\%) & Repeat test (\%) & No action (\%) \\
\hline \multicolumn{6}{|l|}{ Database studies } \\
\hline [14] & USA & PSA $<4$ & 28.6 & & 71 \\
\hline [21] & USA & PSA $<4$ & & 37.7 & \\
\hline \multicolumn{6}{|l|}{ Survey studies } \\
\hline \multirow[t]{2}{*}{ [23] } & UK & $P S A<3$ & 0 & 1.3 & 98.7 \\
\hline & & PSA 0.1-4 & 7 & & \\
\hline [18] & France & NS & & 54.3 & 27.5 \\
\hline \multirow[t]{5}{*}{ [22] } & UK & $P S A \leq 4$ & & 86.9 & \\
\hline & & GPs & & 82.8 & \\
\hline & & General surgeons & & 64.3 & \\
\hline & & Geriatricians & & 89.4 & \\
\hline & & FHSA & & & \\
\hline [17] & Japan & $P S A \leq 4$ & & 17 & \\
\hline
\end{tabular}


Table 4 Follow-up after abnormal PSA values

\begin{tabular}{|c|c|c|c|c|c|c|}
\hline Reference number & Country & PSA Cut off (ng/ml) & Referral (\%) & Repeat test (\%) & No action (\%) & PSA > 10 referral $(\%)$ \\
\hline \multicolumn{7}{|l|}{ Database studies } \\
\hline \multirow[t]{3}{*}{ [14] } & USA & $\mathrm{PSA} \geq 4$ & 51.9 & & 48 & \\
\hline & & Age-specific cut off: & 58 & & 42 & \\
\hline & & $6.5(\geq 75 \mathrm{yr})$ & & & & \\
\hline [24] & Spain & $P S A \geq 4$ & 31 & & 69 & \\
\hline [21] & USA & PSA $\geq 4$ & 86 & 56.1 & & 100 \\
\hline \multicolumn{7}{|l|}{ Survey studies } \\
\hline \multirow[t]{5}{*}{ [23] } & UK & $P S A \geq 3$ & 18.2 & 15.7 & 67 & 82.7 \\
\hline & & $P S A \geq 4$ & 30 & & & \\
\hline & & Mean (calculated) & 28.6 & & & 71.4 \\
\hline & & $50-59$ yr: 6.2 & & & & \\
\hline & & $70-84$ yr: 13 & & & & \\
\hline [18] & France & NS & 10.5 & & & \\
\hline \multirow[t]{6}{*}{ [26] } & UK & Median (calculated) & & & & \\
\hline & & $45 \mathrm{yr}: 4.5$ & & & & \\
\hline & & 55 yr: 5.5 & & & & \\
\hline & & $65 \mathrm{yr}: 6.5$ & & & & \\
\hline & & 75 yr: 6.5 & & & & \\
\hline & & $85 \mathrm{yr}: 7.5$ & & & & \\
\hline$[7]$ & Denmark & mean 5 (calculated) & & & & \\
\hline$[6]$ & Ireland & median 5.4 (calculated) & & 55 & & \\
\hline$[15]^{*}$ & UK & NS & & & & 28 \\
\hline [19] & USA & NS & 33 & & & 93 \\
\hline \multirow[t]{5}{*}{ [22] } & UK & $\mathrm{PSA}>4$ & 85.8 & & & \\
\hline & & GPs & 78.4 & & & \\
\hline & & General surgeons & 85.3 & & & \\
\hline & & Geriatricians & 100 & & & \\
\hline & & FHSA & & & & \\
\hline [17] & Japan & PSA $>4$ & 73 & & & 20 \\
\hline \multirow[t]{6}{*}{ [16] } & USA & PSA 4-10 & Age specific: & & & \\
\hline & & & 50-59 years: 69 & & & \\
\hline & & & 60-69 years: 67 & & & \\
\hline & & & 70-74 years: 58 & & & \\
\hline & & & $75-79$ years: 52 & & & \\
\hline & & & $\geq 80$ years: 45 & & & \\
\hline [20] & USA & NS & Most doctors refer with PSA 4-10 & & & 13 \\
\hline [25] & USA & PSA $>4$ & 67.8 & & & \\
\hline
\end{tabular}

Abbreviations: yr year; NS Not Specified; GP General Practitioner; FHSA Family Health Service Advisor.

* abstract only.

between a mean of $5 \mathrm{ng} / \mathrm{ml}$ to $13 \mathrm{ng} / \mathrm{ml}$ for patients aged 70-84 years old (Table 4) [6,7,23,26].

\section{Repeat testing after normal PSA $(<\mathbf{4} \mathbf{n g} / \mathrm{ml})$}

Repeat testing varied greatly also. One UK survey showed a high repeat rate reported by all physicians [22], while a
French survey reported that $72.5 \%$ of the physicians (GPs) took further action after a normal PSA result [18]. Also, in a US survey, 29\% of the PCPs reported advising yearly screening for prostate cancer, even in patients older than 80 years, with GPs advising this more often than internists/medical subspecialists (55.6\% vs $13.3 \%$ ) [25]. 


\section{Repeat testing after moderately abnormal PSA ( $\geq 4 \mathrm{ng} / \mathrm{ml}$ )}

Only one database study from the USA described that in $56 \%$ of the cases requested by internists an abnormal PSA value was repeated, while $86 \%$ were referred [21].

Repeat testing was also described in two European studies, but reported cut-off values differed. One survey study defined PSA $\geq 3 \mathrm{ng} / \mathrm{ml}$ as abnormal (15.7\% repeat testing by GPs) and the second survey study reported a median cut-off of $5.4 \mathrm{ng} / \mathrm{ml}$ ( $55 \%$ repeat testing by GPs) $[6,23]$.

\section{Reasons for repeating and time frame for follow-up}

No reasons for referral or repeat testing after an initially normal PSA value were described in the studies included.

Only one survey described the reasons physicians had for not referring after a primary elevated PSA value; the PSA value was considered too low in $70.5 \%$ (all $<10 \mathrm{ng} / \mathrm{ml}$ ), comorbidity too high in $3.6 \%$ and other reasons in $4.2 \%$ [23]. No time frame for conducting follow-up was reported.

\section{Discussion}

This is the first systematic review of the literature focusing on follow-up policy after a normal or elevated PSA test by GPs and non-urologic hospitalists. Only 15 studies were published on this topic, most of which were of low quality. Furthermore, a large variety of opinions and policies used by general practitioners and non-urologic hospitalists were described on follow-up after a normal or an abnormal PSA test result. Only four studies researched cut-off values for referral or repeat testing. Reasons for repeating a PSA test after an initial normal result were not described (although two studies described testing PSA yearly). Only one study mentioned the reasons for not referring patients after an abnormal PSA test. A time frame for repeating a test was mentioned in none of the studies. Therefore, the strongest conclusion of this systematic review is that there is a large variety in follow-up after primary PSA testing.

\section{Selection of studies and quality assessment}

We conducted this systematic review according to the proposed guidelines [27]. We believe that our search strategy was adequate, because we used broad search terms and only one additional study was included after checking the reference lists of the included studies. A limitation of this study is the small number of studies that was found and the exclusion of one Japanese study due to language restrictions.

We have arbitrarily chosen a cut-off value of $75 \%$ for the definition of high quality studies. We could not apply quality scores in further analyses, due to the wide variety of PSA testing policies and the few data this generated. Therefore, we refrained from pooling the data and performing meta-analyses.

The interpretation of our results may be limited to the differences in study design. Database studies may describe follow-up policies more accurately than survey studies do, as the latter may include socially acceptable answers instead of describing the physicians' true actions. The number of studies included was too small to uncover this - expected - effect of study design on the results.

\section{Referral after normal PSA test}

After a normal PSA test around $7-10 \%$ of the patients are referred to a urologist in all physician groups. Referral after an initially normal PSA value seems to have decreased over time, described by database studies in the USA $[14,21]$ and survey studies in UK $[22,23]$. A possible explanation for this finding is that patients may be referred for other reasons than the PSA value, for instance because of the presence of therapy resistant LUTS.

\section{Referral after moderately abnormal PSA test \\ (PSA $\geq 4 \mathrm{ng} / \mathrm{ml}$ )}

Non-urologic hospitalists appeared to refer more patients after an abnormal PSA test than GPs, but seem to refer about as often as PCPs. Only one study described followup by non-urologic hospitalists, but this study also showed quite high referral rates for GPs [22].

More patients were referred in the USA [14,16,19,21,25] than in Spain [24]. These differences between countries may reflect differences in local guidelines. Until 2009 the AUA guideline on PSA testing recommended PSA testing for patients 50 years or older with a life expectancy of 10 years or more [28], while the EAU guideline does not recommend such screening behavior [29].

In the USA, referral rates differed over time (19951998) $[14,16,19,21]$, which could not be explained by a change in guidelines, but might be explained by the different designs of these four studies.

In the included survey studies a small group of about $20 \%$ of physicians report only referring after a PSA value $>10 \mathrm{ng} / \mathrm{ml}[15,17,20]$. All guidelines advise to follow-up an elevated PSA value, but do not mention how or when follow-up after an abnormal PSA test should be conducted.

Only one study mentioned the reasons for not referring after an abnormal PSA test. The main reason was that the PSA value was considered too low, but comorbidity also played a role. Another reason might be that the interpretation and further management of abnormal test results are strongly affected by the physicians' estimation of pretest disease probability [30]. It is not mentioned if 
these patients underwent repeat testing. By not conducting follow-up testing physicians seem to imply that an abnormal PSA value holds no consequences for these patients. Maybe these PSA tests could have been omitted, because knowing your PSA value to be elevated, can cause a lot of (unnecessary) distress in patients [31].

\section{Repeat testing after normal PSA test}

Repeat PSA testing after a normal PSA test varied greatly. It seemed to be widely used in the USA (as recommended by the AUA guidelines) as well as in the UK $[22,25]$, and to a lesser extent also in France [18], which is not in accordance with the EAU guidelines. At least two studies (one UK, one USA) reported that physicians agree with screening by an annual PSA test $[22,25]$, which is not in accordance with the European guidelines.

All of the studies included and all of the reported guidelines were published before the recent presentation of the ERSPC and the publication of the results of the Prostate, Lung, Colorectal and Ovarian (PLCO) Cancer Screening Trial. Before the publication of the ERSPC and PLCO results there was no clear evidence on the effect of PSA testing. This resulted in different opinions and consecutively different guidelines on PSA testing, not only between but also within countries. The ERSPC showed that PSA-based screening may reduce prostate cancer mortality by $20 \%$, but it remained unclear which patients may benefit from screening [3]. However, the PLCO trial did not show a mortality reduction [32]. Also, a recent meta-analyses on the effect of population based screening showed no significant effect on mortality [33]. We believe that these studies are important to take into account when considering PSA testing in men who request this. Recently, the US Preventive Services Task Force postulated a negative advice on PSA testing [34].

In survey studies, participants may provide desirable answers, which are not in line with their daily practice. We have found no study to support this suggestion.

\section{Conclusions}

Our study shows that follow-up after a normal or raised PSA test by GPs and non-urologic hospitalists varies greatly and seems not to be in accordance with practice guidelines. This could mean suboptimal treatment for some patients and possibly unnecessary distress in others. Further research is necessary to assess the reasons for this follow-up policy.

\section{Additional file}

Additional file 1: Appendix 1. Search terms. Appendix 2. Quality score criteria and informativity.

\section{Abbreviations}

PSA: Prostate specific antigen; LUTS: Lower urinary tract symptoms; BPH: Benign prostate hyperplasia; AUA: American Urological Association; DRE: Digital rectal examination; EAU: European Association of Urology; GPs: General practitioners; PCPs: Primary care practitioners; ERSPC: European Randomized study of Screening for Prostate Cancer; PLCO: Prostate, Lung, Colorectal and Ovarian Cancer Screening Trial.

\section{Competing interests}

The authors declare that they have no competing interests.

\section{Authors' contributions}

SM carried out the systematic review with SAML. This was supervised by $\mathrm{MHH}$ and $\mathrm{MHB}$. Study design and data processing were evaluated by $\mathrm{MHH}$, MHB, RMN, KM and JEHMH. They also helped SM in drafting this manuscript. All authors read and approved the final manuscript

\section{Acknowledgements}

There was no funding for this study.

We would like to thank Mirell Papenhuijzen, librarian and head of the DISC (Documentation, Information and Study Center) at the Isala clinics for helping us clarify the search terms.

\section{Author details}

'Isala clinics, Department of Urology, Groot Wezenland 20, 8011, JW, Zwolle, The Netherlands. ${ }^{2}$ Department of General Practice, University of Groningen, University Medical Center Groningen, Hanzeplein 1, P.O.Box 30.001, 9700, RB, Groningen, The Netherlands. ${ }^{3}$ Department of Urology, University of Groningen, University Medical Center Groningen, Hanzeplein 1, P.O.Box 30.001, 9700, RB, Groningen, The Netherlands. ${ }^{4}$ University of Groningen, University Medical Center Groningen, Psychosocial services Hanzeplein 1, P.O. Box 30.001, 9700, RB, Groningen, The Netherlands.

Received: 24 April 2012 Accepted: 1 October 2012

Published: 11 October 2012

\section{References}

1. Vedel I, Puts MTE, Monette M, Monette J, Bergman H: The decision-making process in prostate cancer screening in primary care with a prostatespecific antigen: A systematic review. J Geriatr Oncol 2011, 2011. doi:http://dx.doi.org/10.1016/j.jgo.2011.04.001.

2. Djulbegovic M, Beyth RJ, Neuberger MM, Stoffs TL, Vieweg J, Djulbegovic B, Dahm P: Screening for prostate cancer: systematic review and meta-analysis of randomised controlled trials. BMJ 2010, 2010 doi:http://dx.doi.org/10.1136/bmi.c4543.

3. Schröder FH, Hugosson J, Roobol MJ, Tammela TL, Ciatto S, Nelen V, Kwiatkowski M, Lujan M, Lilja H, Zappa M, Denis $\sqcup$, Recker F, Berenguer A, Määttänen L, Bangma CH, Aus G, Villers A, Rebillard X, Van der Kwast T, Blijenberg BG, Moss SM, De Koning HJ, Auvinen A: Screening and prostate-cancer mortality in a randomized European study. N Engl J Med 2009, 360:1320-1328.

4. Bunting PS, Goel V, Williams JI, Iscoe NA: Prostate-specific antigen testing in Ontario: Reasons for testing patients without diagnosed prostate cancer. CMAJ 1999, 160:70-75.

5. Horninger W, Reissigl A, Rogatsch H, Volgger H, Studen M, Klocker $H_{\text {, }}$ Bartsch G: Prostate cancer screening in the Tyrol, Austria: experience and results. Eur J Cancer 2000, 36:1322-1335.

6. Little B, Ho KJ, Gormley G, Young M: PSA testing in general practice. Prostate Canc Prostatic Dis 2003, 6:154-158.

7. Jønler MEB, Poulsen J: Prostate-specific antigen testing in general practice: A survey among 325 general practitioners in Denmark. Scand J Urol Nephrol 2005, 39:214-218.

8. Thompson IM, Ankerst DP: Prostate-specific antigen in the early detection of prostate cancer. CMAJ 2007, 176:1853-1858.

9. Greene KL, Albertsen PC, Babaian RJ, Carter HB, Gann PH, Han M, Kuban DA, Sartor AO, Stanford JL, Zietman A, Carroll P: Prostate specific antigen best practice statement: 2009 update. J Urol 2009, 182:2232-2241.

10. Heidenreich A, Aus G, Bolla M, Joniau S, Matveev VB, Schmid HP, Zattoni F: EAU guidelines on prostate cancer. Eur Urol 2008, 53:68-80. 
11. Horwich A, Parker C, Kataja V: Prostate cancer: ESMO clinical recommendations for diagnosis, treatment and follow-up. Ann Oncol 2008, 19(Suppl 2):ii45-ii46.

12. Harden A, Garcia J, Oliver S, Rees R, Shepherd J, Brunton G, Oakley A: Applying systematic review methods to studies of people's views: an example from public health research. J Epidemiol Commun Health 2004, 58:794-800.

13. Prins J, Blanker MH, Bohnen AM, Thomas S, Bosch JL: Prevalence of erectile dysfunction: a systematic review of population-based studies. Int I Impot Res 2002, 14:422-432.

14. Dyche DJ, Ness J, West M, Allareddy V, Konety BR: Prevalence of Prostate Specific Antigen Testing for Prostate Cancer in Elderly Men. J Urol 2006, 175:2078-2082.

15. Eddy BKC, Miller P, Rane A: Are GPs referring efficiently for prostate cancer? A primary care audit. BJU Int 2002, 90:44.

16. Fowler FJ Jr, Bin L, Collins MM, Roberts RG, Oesterling JE, Wasoon JH, Barry MJ: Prostate cancer screening and beliefs about treatment efficacy: a national survey of primary care physicians and urologists. Am J Med 1998, 104:526-532

17. Fukagai T, Maruyama K, Nagata M, Morita M, Naoe M, Yoshida H: Practice patterns regarding prostate cancer and benign prostatic hyperplasia in Japanese primary care practitioners. Int J Urol 2007, 14:412-415.

18. Guy L, van de Steene E, Vedrine N, Teissonniere M, Boiteux JP: General practical survey of individual prostate cancer screening. Prog Urol 2008, 18:46-52.

19. Hicks RJ, Hamm RM, Bemben DA: Prostate cancer screening. What family physicians believe is best. Arch Fam Med 1995, 4:317-322.

20. Hoffman RM, Buller DB, Papenfuss MR, Moon TE: Attitudes and practices of primary care physicians for prostate cancer screening. Am J Prev Med 1996, 12:277-281.

21. Hoffman RM BP, Gilliland F: Prostate-specific antigen testing practices and outcomes. J Gen Intern Med 1998, 13:106-110.

22. Kirby RS CG, Chapple C, Hudd C, Swallow M, Shore D: Shared care between general practitioners and urologists in the management of benign prostatic hyperplasia: a survey of attitudes among clinicians. $J R$ Soc Med 1995, 88:284-288.

23. Melia JCP, Coleman D, Moss S: Urological referral of asymptomatic men in general practice in England. Br J Cancer 2008, 98:1176-1181.

24. Oller Colom M, Jimenez Navarrete S, Hidalgo Garcia A, Calvo Rosa E, Pérez Herrera MM, Castellanos Duarte RM, Simón Muela Cl, Asens Mampel N, Duaso Allué I, Gascón Gazulla S: Attitude of primary care physicians to early detection of prostatic cancer through prostate-specific antigen. Aten Primaria 2000, 26:323-326

25. Plawker MWFJ, Nitti WW, Macchia RJ: Primary care practitioners: an analysis of their perceptions of voiding dysfunction and prostate cancer. J Urol 1996, 155:601-604.

26. Rochester MA DP, McLoughlin J: Perception of abnormal serum prostatespecific antigen (PSA) test results amongst family practitioners. Ann $R$ Coll Surg Engl 2008, 90:398-402.

27. Stroup DF, Berlin JA, Morton SC, Ingram Olkin I, Williamson GD, Rennie D, Moher D, Becker BJ, Sipe TA, Thacker SB: Meta-analysis of observational studies in epidemiology: a proposal for reporting. JAMA 2000, 283:2008-2012.

28. American Urological Association (AUA): Prostate-specific antigen (PSA) best practice policy. Oncology 2000, 14:267-272. 277-278, 280 passim.

29. Aus G, Abbou CC, Pacik D, Schmid HP, Van Poppel H, Wolff JM, Zattoni F: EAU guidelines on prostate cancer. Eur Urol 2001, 40:97-101.

30. Houben PH, van der Weijden T, Winkens B, Winkens RA, Grol RP: Pretest expectations strongly influence interpretation of abnormal laboratory results and further management. BMC Fam Pract 2010, 13.

31. Dale WBP, Han M, Meltzer D: The role of anxiety in prostate carcinoma: a structured review of the literature. Cancer 2005, 104:467-478.

32. Andriole GL, Crawford ED, Grubb RL, et al: Mortality results from a randomized prostate-cancer screening trial. N Engl J Med 2009, 360:1310-1319.

33. Djulbegovic MBR, Neuberger MM, Stoffs TL, Vieweg J, Djulbegovic B, Dahm $P$ : Screening for prostate cancer: systematic review and meta-analysis of randomised controlled trials. BMJ 2010, c4543.

34. Chou R, Croswell JM, Dana T, et al: Screening for prostate cancer: a review of the evidence for the US Preventive Services Task Force. Ann Intern Med 2011, 155:762-771.

doi:10.1186/1471-2296-13-100

Cite this article as: Van der Meer et al.: Prostate specific antigen testing policy worldwide varies greatly and seems not to be in accordance with guidelines: a systematic review. BMC Family Practice 2012 13:100.

\section{Submit your next manuscript to BioMed Central and take full advantage of:}

- Convenient online submission

- Thorough peer review

- No space constraints or color figure charges

- Immediate publication on acceptance

- Inclusion in PubMed, CAS, Scopus and Google Scholar

- Research which is freely available for redistribution 